\title{
Social support and care needs of the disabled elderly population: An empirical study based on survey data from Beijing, China
}

\author{
Xiaoning Hao ${ }^{1,2, *}$, Juan $\mathrm{Gu}^{3}$, Xiangji Ying ${ }^{1}$, Tao Bo ${ }^{4}$, Wei Fu ${ }^{1}$ \\ ${ }^{1}$ China National Health Development Research Center, National Health and Family Planning Commission, Beijing, China; \\ ${ }^{2}$ School of Public Health, Shandong University, Jinan, Shandong, China; \\ ${ }^{3}$ School of Public Administration, Chongqing University, Chongqing, China; \\ ${ }^{4}$ College of Politics and Public Administration, Qingdao University, Qingdao Shandong, China.
}

\begin{abstract}
Summary
In order to describe and examine differences in social support and care needs among disabled Chinese elderly, the current study used stratified sampling to survey local residents of Beijing age 60 or over in the districts of Xicheng, Chaoyang, and Tongzhou in 2016. Structured in-person interviews were conducted with a 7-domain questionnaire. Multiple logistic regressions were used to compare social support and care needs among functioning, partially disabled, and completely disabled elderly. All statistical analyses were performed using SPSS 19.0 with a significance level of 0.05 (two-sided). One thousand and eightythree residents completed the survey. Based on Activities of Daily Living (ADL) scores, $736(68.0 \%)$ respondents were functioning (ADL score $=14), 167(15.4 \%)$ were partially disabled (14 < ADL score < 22), and $180(16.6 \%)$ were fully disabled (ADL score $\geq 22)$. Most of the disabled had formal financial support, they received daily care at home, and they received modest emotional support. After controlling for confounding factors, fully disabled respondents were 2.35 times $(p=\mathbf{0 . 0 1 8})$ more likely to receive financial support and 3.65 times $(p=0.003$ ) more likely to receive emotional support than functioning respondents. However, the fully functioning and partially disabled did not differ significantly in terms of financial or emotional support. Compared to fully functioning respondents, partially disabled respondents were $0.49(p<0.001)$ times less likely to be fully satisfied with their daily care while fully disabled respondents were $0.37(p<0.001)$ times less likely to be fully satisfied with that care. The current study provided a thorough depiction of the current status of social support and care needs of disabled Chinese elderly. More attention should be paid to social support for the partially disabled and daily care for both the partially and fully disabled.
\end{abstract}

Keywords: Disabled elderly, social support, population aging

\section{Introduction}

China is witnessing the aging of its population. The country now has the largest population age 60 or over of any country worldwide. In 2015, its population age 60 or over was 211.9 million, accounting for approximately $15 \%$ of the total population (1).

*Address correspondence to:

Dr. Hao Xiaoning, China National Health Development Research Center, National Health and Family Planning Commission, Beijing 100191, China.

E-mail: xnhao5421@163.com
Meanwhile, aging in China has occurred faster than in any other country. The population age 60 or over is expected to account for $35 \%$ of the total population by 2050 (1).

Functional ability or disability has been identified as an indicator of overall health status among older adults. The disabled elderly need to receive support and care from family members, relatives, and society for the rest of their lives. According to survey data from the China National Committee on Aging, there were approximately 33.5 million partially or fully disabled elderly living in urban or rural areas of China by the end of 2010; these individuals accounted for $19 \%$ of the total elderly 
population and included 10.8 million elderly who were fully disabled and who represented $6.25 \%$ of all elderly (2). The Report on China's Efforts to Address Aging (2013) indicated that the number of disabled elderly in China has been increasing and reached 37.5 million in 2013 (3).

The association between social support and functional ability has garnered increased attention due to rapid population aging around the world. Except for a few studies (4), most studies have found high levels of social support and connections help sustain good health and functional ability, along with other physiological and behavioral factors (5-11). Numerous studies have identified several components of social support that are associated with future functional status, including financial support, instrumental support such as house-cleaning, preparing meals, and provision of transportation (12,13), as well as emotional support (14).

Most previous studies have focused on finding social support factors that predict future functional ability among elderly, whereas few have focused on the status of social support of disabled older adults. The current study therefore aims to describe and examine differences in the extent of social support among disabled elderly in the Beijing area to help create a better social support system for the disabled older population in China.

\section{Materials and Methods}

\subsection{Data collection}

This study was conducted from February 2016 until the end of April 2016. Individuals age 60 or over who lived in the districts of Xicheng (including the former Xuanwu district), Chaoyang, and Tongzhou of Beijing were surveyed. Beijing was chosen as the survey site because of the prominent aging of its population. A variety of neighborhoods were sampled, including recently constructed neighborhoods, old neighborhoods, suburban neighborhoods, mixed neighborhoods, and villages. The current study used two-stage sampling. First, two urban districts (Xicheng and Chaoyang) and one suburban district (Tongzhou) were chosen in light of Beijing's functional districts. Neighborhoods from the districts were then chosen and equidistant sampling was used to select families from these neighborhoods to serve as the final sample. Data were obtained through structured face-to-face interviews with a 7-domain questionnaire. The research team provided quality control and 20 investigators visited homes to conduct interviews. Of 1,185 potential participants, 1,085 individuals agreed to participate in this study (response rate: $91.6 \%$ ).

\subsection{Measures}

\subsubsection{Activities of Daily Living (ADL) Scale score}

The definition of disability is inconsistent across the domestic and international literature. In aging studies and practical applications, disability usually refers to an inability of elderly individuals to continue living independently. ADL scales have been widely used around the world as an effective measurement tool to assess the extent of disability among the elderly, which contain two parts, the Physical Self-Maintenance Scale (PSMS) and the Instrumental Activities of Daily Living (IADL) Scale, originally developed by Lawton and Brody in 1969 (15). Accordingly, the current survey consisted of 14 items to assess disability and was divided into two parts: one was the PSMS, which includes six domains - toilet use, eating, dressing, grooming, walking, and bathing, and the other was the IADL Scale, which includes eight dimensions ability to use a telephone, shopping, food preparation, housework, laundry, mode of transportation, responsibility for taking one's own medications, and the ability to handle one's finances. Each question on the scale was scored from 1 (indicating complete functioning) to 4 (indicating complete disability). The total score ranged from 14 to 56 . A total score of 14 points indicates complete functioning, a score between 15 and 21 indicates disability to some extent, and a score $\geq 3$ on two or more questions or total score $>22$ indicates complete disability.

\subsubsection{Social support}

The definition and measures of social support are similarly inconsistent across the literature (16). In the current study, social support was defined as "elderly receiving support from other people, organizations, or society, including financial support, routine support, and emotional support, as part of their daily lives or when they face a crisis". Variables for social support were thus divided into three categories: financial support, routine support, and emotional support. Based on the extent to which support was official, social support was also classified as formal or informal support (this mainly applied to financial support). Formal financial support (e.g. a salary, pension, or earnings) is the main source of funds for the elderly while informal financial support, usually from a spouse, son(s)/daughter(s), grandchildren, or other relatives, is an important source of funds for the elderly. Table 1 shows the categories of social support and variables for needs.

\subsection{Data processing and analysis}

EpiData 3.1 was used to create a database. Data entry was completed by two independent research assistants and a logical review was conducted by a third member of the research team. Descriptive statistical analysis, chi-square tests, and logistic regression analysis were performed using SPSS 19.0 with a significance level 
Table 1. Categories of social support and variables for care needs

\begin{tabular}{lll}
\hline Type & Variable & Applicable questions \\
\hline Financial support & Variables for financial support & $\begin{array}{l}\text { Disposable income } \\
\text { Financial status } \\
\text { Satisfaction with medical insurance coverage } \\
\text { Salary, pension, etc. }\end{array}$ \\
& Formal financial support & $\begin{array}{l}\text { Having medical insurance } \\
\text { Source of funds }\end{array}$ \\
Routine support & Routine support & Living arrangements \\
& & $\begin{array}{l}\text { Receiving help from son(s)/daughter(s) } \\
\text { Main caregiver when sick } \\
\text { Satisfaction with the quality of care provided by a caregiver }\end{array}$ \\
& & Number of close friends \\
Emotional support & Willingness to ask for help from son(s)/daughter(s) \\
& Relationship with neighbors
\end{tabular}

Table 2. ADL scale score for respondents as a whole and by gender $(n=1,083)$

\begin{tabular}{lrrrr}
\hline ADL category* & Total & Male & Female & Percentage $(\%)$ \\
\hline ADL score $=14$ & 736 & 388 & 348 & 68.0 \\
$14<$ ADL score $<22$ & 167 & 70 & 97 & 15.4 \\
ADL score $\geq 22$ & 180 & 82 & 98 & 16.6 \\
Total & 1,083 & 540 & 543 & 100 \\
\hline
\end{tabular}

*ADL scale score $=14$ : fully functioning; $14<$ ADL score $<22$ : partially disabled; ADL score $\geq 22$ : fully disabled. ADL, Activities of Daily Living.

of 0.05 (two-sided). Relevant variables were converted when necessary.

\section{Results}

\subsection{Descriptive statistics}

Of 1,085 elderly who initially agreed to participate in this study, 1,083 completed the survey $(n=350$ in Xicheng and Xuanwu, $n=506$ in Chaoyang, and $n=$ 227 in Tongzhou). Of the respondents, 736 (68.0\%) were fully functioning (ADL score of 14 points; 388 males, 348 females), 167 (15.4\%) were partially disabled (14 points $<$ ADL score $<22$ points; 70 males, 97 females), and 180 (16.6\%) were fully disabled (ADL score $\geq 22$ points; 82 males, 98 females) (Table 2). Results indicated that female respondents had a greater level of disability than male respondents.

Table 3 shows descriptive statistics regarding the disabled elderly. Disabled adults over the age of 70 accounted for $89 \%$ of the sample. Elderly respondents were less able to live alone and were more likely to be disabled with increasing age. Eight percent of respondents ages 60-69 were disabled, 38.7\% of respondents ages $70-79$ were disabled, and $80.3 \%$ of respondents age 80 or over were disabled. Elevenpoint-five percent of the disabled elderly had no chronic diseases. A higher percentage of the fully disabled elderly had more than three chronic diseases $(52.8 \%)$ in comparison to the partially disabled elderly (38.9\%).
A point worth mentioning is that the self-rated ability to live independently was greater than the score on the ADL scale. Only $1.4 \%$ respondents described themselves as fully disabled. However, $16.5 \%$ of respondents were fully disabled according to the ADL scale.

\subsection{Current status of social support among disabled Chinese elderly}

\subsubsection{Financial support}

Table 4 shows the current status of financial, routine, and emotional support by the extent of disability. Most of the disabled elderly $(92.2 \%$ of the fully disabled, $90.4 \%$ of the partially disabled) responded that they had a middle or low level of monthly disposable income (in US dollars). Prior group interviews indicated that some elderly individuals had financial problems if they did not have a pension and they relied solely on government subsidies. When asked to rate their financial status, $46.7 \%$ of the partially disabled elderly and $45 \%$ of the fully disabled elderly responded they could basically balance their income and expenditures. Seventeen percent of the partially disabled elderly and $24.6 \%$ of the fully disabled elderly responded that they were currently struggling financially and could not balance their income and expenditures. This apparent difference between partially and fully disabled elderly in terms of self-perceived financial difficulty might be 
Table 3. Baseline characteristics of the disabled elderly in Beijing $(n=347)$

\begin{tabular}{|c|c|c|c|c|c|c|}
\hline \multirow{2}{*}{ Item } & \multicolumn{2}{|c|}{ Total $(n=347)$} & \multicolumn{2}{|c|}{ Partially disabled elderly $(n=167)$} & \multicolumn{2}{|c|}{ Fully disabled elderly $(n=180)$} \\
\hline & $n$ & $\%$ & $n$ & $\%$ & $n$ & $\%$ \\
\hline \multicolumn{7}{|l|}{ Gender } \\
\hline Female & 195 & 56.2 & 97 & 58.1 & 98 & 54.4 \\
\hline \multicolumn{7}{|l|}{ Age } \\
\hline 60-69 & 38 & 11.0 & 29 & 17.4 & 9 & 5 \\
\hline $70-79$ & 166 & 47.8 & 97 & 58.1 & 69 & 38.3 \\
\hline$\geq 80$ & 143 & 41.2 & 41 & 24.5 & 102 & 56.7 \\
\hline \multicolumn{7}{|l|}{ Marital status } \\
\hline Spouse & 177 & 51.0 & 105 & 62.9 & 72 & 40.0 \\
\hline No spouse & 170 & 49.0 & 62 & 37.1 & 108 & 60.0 \\
\hline \multicolumn{7}{|l|}{ Level of education } \\
\hline Less than primary school & 254 & 73.2 & 110 & 65.9 & 144 & 80.0 \\
\hline Middle school & 80 & 23.1 & 48 & 28.7 & 32 & 17.8 \\
\hline College or higher & 13 & 3.7 & 9 & 5.4 & 4 & 2.2 \\
\hline \multicolumn{7}{|l|}{ Income (per month, in USD) } \\
\hline$<300$ & 158 & 45.5 & 69 & 41.3 & 89 & 49.4 \\
\hline $301-500$ & 119 & 34.3 & 64 & 38.3 & 55 & 30.6 \\
\hline $501-600$ & 40 & 11.5 & 18 & 10.8 & 22 & 12.2 \\
\hline$\geq 601$ & 30 & 8.6 & 16 & 9.6 & 14 & 7.8 \\
\hline \multicolumn{7}{|l|}{ Number of diseases } \\
\hline None & 40 & 11.5 & 22 & 13.2 & 18 & 10.0 \\
\hline 1 & 64 & 18.4 & 31 & 18.6 & 33 & 18.3 \\
\hline 2 & 83 & 23.9 & 49 & 29.3 & 34 & 18.9 \\
\hline$\geq 3$ & 160 & 46.1 & 65 & 38.9 & 95 & 52.8 \\
\hline
\end{tabular}

due to the fact that the fully disabled elderly had higher medical expenses as part of their daily lives than the partially disabled elderly had. Respondents described their out-of-pocket medical expenditures as 4,053 yuan on average, accounting for $31 \%$ of the total treatment costs. One hundred and sixty-five fully disabled elderly and 177 partially disabled elderly answered the question "how satisfied are you with your medical insurance coverage?" Fifty-one-point-five percent of the fully disabled and $54.8 \%$ of the partially disabled responded that they were "somewhat satisfied" or "dissatisfied".

As shown in Table 4, 69.7\% of the disabled elderly had formal financial support such as a salary or pension (71.9\% of the partially disabled elderly, $67.8 \%$ of the fully disabled elderly). Ninety-eight-point-six percent of the disabled elderly participated in medical insurance $(98.8 \%$ of the partially disabled elderly, $98.3 \%$ of the fully disabled elderly). The top two types of insurance that most respondents had were Urban Employee Medical Insurance (57\% of all respondents, $60.6 \%$ of the partially disabled elderly, $53.7 \%$ of the fully disabled elderly) and New Rural Cooperative Medical Insurance $(22.5 \%$ of all respondents, $23 \%$ of the partially disabled elderly, $22 \%$ of the fully disabled elderly). Other types of insurance included Serious Illness Insurance for the Elderly and Elderly-Children Insurance.

In terms of informal financial support, $61.1 \%$ of the disabled elderly received financial help from the local government or community $(61.7 \%$ of the partially disabled elderly, $60.3 \%$ of the fully disabled elderly). Thirty-point-five percent of the disabled elderly received financial help from their son(s)/daughter(s) (27.7\% of the partially disabled elderly, $32.8 \%$ of the fully disabled elderly), and $8.4 \%$ received financial help from their spouses $(10.2 \%$ of the partially disabled elderly, $6.9 \%$ of the fully disabled elderly). None $(0 \%)$ of the partially or fully disabled elderly received financial help from their grandchildren or other relatives.

\subsubsection{Routine support}

Overall, most elderly individuals lived with family. Although $10.1 \%$ of the elderly lived alone, most lived with immediate family, relatives, or a care worker (92.2\% of the partially disabled elderly, $87.8 \%$ of the fully disabled elderly). Eighty-four-point-one percent of the disabled elderly (two partially disabled elderly individuals with no son(s)/daughter(s)) responded that they could often receive help from their son(s)/ daughter(s) $(81.8 \%$ of the partially disabled elderly, $86.1 \%$ of the fully disabled elderly), $14.8 \%$ responded that they could occasionally receive help from their son(s)/daughter(s) (16.4\% of the partially disabled elderly, $13.3 \%$ of the fully disabled elderly), and $1.1 \%$ responded that they could not receive help from their son(s)/daughter(s) (1.8\% of the partially disabled elderly, $0.6 \%$ of the fully disabled elderly). Most elderly chose their son(s)/daughter(s) $(58.7 \%$ of the partially disabled elderly, $75.6 \%$ of the fully disabled elderly) as their main caregiver when sick, followed by their spouse $(38.3 \%$ of the partially disabled elderly, $20.6 \%$ of the fully disabled elderly). One-point-eight percent 
Table 4. Descriptive statistics regarding social support for the disabled elderly in Beijing $(n=347)$

\begin{tabular}{|c|c|c|c|c|c|c|}
\hline \multirow{2}{*}{ Item } & \multicolumn{2}{|c|}{ Total $(n=347)$} & \multicolumn{2}{|c|}{ Partially disabled $(n=167)$} & \multicolumn{2}{|c|}{ Fully disabled $(n=180)$} \\
\hline & $n$ & $\%$ & $n$ & $\%$ & $n$ & $\%$ \\
\hline \multicolumn{7}{|l|}{ Financial support } \\
\hline \multicolumn{7}{|l|}{ Disposable monthly income } \\
\hline Low $(<300$ USD $)$ & 158 & 45.5 & 69 & 41.3 & 89 & 49.4 \\
\hline Middle (301-600 USD) & 159 & 45.8 & 82 & 49.1 & 77 & 42.8 \\
\hline High (> 601 USD) & 30 & 8.6 & 16 & 9.6 & 14 & 7.8 \\
\hline \multicolumn{7}{|l|}{ Financial status } \\
\hline Well-off & 127 & 36.6 & 72 & 43.1 & 55 & 30.6 \\
\hline Modest & 159 & 45.8 & 78 & 46.7 & 81 & 45.0 \\
\hline Struggling & 61 & 17.6 & 17 & 10.2 & 44 & 24.4 \\
\hline \multicolumn{7}{|l|}{ Satisfaction with medical insurance coverage* } \\
\hline Fully satisfied & 160 & 46.1 & 80 & 48.5 & 80 & 45.2 \\
\hline Somewhat satisfied & 109 & 31.4 & 55 & 33.3 & 54 & 30.5 \\
\hline Dissatisfied & 73 & 21.0 & 30 & 18.2 & 43 & 24.3 \\
\hline \multicolumn{7}{|l|}{ Formal financial support } \\
\hline Have a salary, pension, etc. (yes) & 242 & 69.7 & 120 & 71.9 & 122 & 67.8 \\
\hline Have medical insurance (yes) & 342 & 98.6 & 165 & 98.8 & 177 & 98.3 \\
\hline \multicolumn{7}{|l|}{ Informal financial support } \\
\hline \multicolumn{7}{|l|}{ Source of funds } \\
\hline Local government or community & 212 & 61.1 & 103 & 61.7 & 109 & 60.3 \\
\hline Son(s)/daughter(s) & 106 & 30.5 & 47 & 27.7 & 59 & 32.8 \\
\hline Spouse & 29 & 8.4 & 17 & 10.2 & 12 & 6.9 \\
\hline Grandchildren or other relatives & 0 & 0 & 0 & 0 & 0 & 0 \\
\hline \multicolumn{7}{|l|}{ Routine support } \\
\hline \multicolumn{7}{|l|}{ Living arrangements } \\
\hline Living alone & 35 & 10.1 & 13 & 7.8 & 22 & 12.2 \\
\hline Residing with relatives & 312 & 89.9 & 154 & 92.2 & 158 & 87.8 \\
\hline \multicolumn{7}{|l|}{ Receiving help from son(s)/daughter(s) } \\
\hline Often & 290 & 83.6 & 135 & 81.8 & 155 & 86.1 \\
\hline Occasionally & 51 & 14.7 & 27 & 16.4 & 24 & 13.3 \\
\hline Never & 4 & 1.2 & 3 & 1.8 & 1 & 0.6 \\
\hline \multicolumn{7}{|l|}{ Main caregiver when sick } \\
\hline Spouse & 101 & 29.1 & 64 & 38.3 & 37 & 20.6 \\
\hline Son(s)/daughter(s) & 234 & 67.4 & 98 & 58.7 & 136 & 75.6 \\
\hline Someone else & 9 & 2.6 & 2 & 1.2 & 7 & 3.9 \\
\hline None & 3 & 0.9 & 3 & 1.8 & 0 & 0 \\
\hline \multicolumn{7}{|l|}{ Satisfaction with the quality of care } \\
\hline Fully satisfied & 136 & 39.2 & 70 & 43.2 & 66 & 36.7 \\
\hline Somewhat satisfied & 189 & 54.5 & 83 & 51.2 & 106 & 58.9 \\
\hline Dissatisfied & 17 & 4.9 & 9 & 5.6 & 8 & 4.4 \\
\hline \multicolumn{7}{|l|}{ Emotional support } \\
\hline \multicolumn{7}{|l|}{ Number of close friends } \\
\hline 0 & 65 & 18.7 & 12 & 7.2 & 53 & 29.4 \\
\hline $1-2$ & 96 & 27.7 & 47 & 28.1 & 49 & 27.2 \\
\hline $3-5$ & 160 & 46.1 & 96 & 57.5 & 64 & 35.6 \\
\hline$\geq 6$ & 26 & 7.5 & 12 & 7.2 & 14 & 7.8 \\
\hline Willingness to ask for son(s)/daughter(s)' help (yes) & 318 & 91.6 & 146 & 88.5 & 172 & 95.6 \\
\hline \multicolumn{7}{|l|}{ Relationship with neighbors } \\
\hline Amicable & 196 & 56.5 & 104 & 62.3 & 92 & 51.1 \\
\hline Passing acquittance only & 93 & 26.8 & 47 & 28.1 & 46 & 25.6 \\
\hline Poor & 58 & 16.7 & 16 & 9.6 & 42 & 23.3 \\
\hline
\end{tabular}

${ }^{*}$ Refers to the elderly who choose to purchase medical insurance.

of the partially disabled elderly had no caregiver or received care from a nurse/social services while $2.6 \%$ of the fully disabled elderly had no caregiver or received care from a nurse/social services. One could argue that the main caregiver for the disabled elderly was a family member and that the community and other social factors had a limited influence. Most of the disabled elderly were fully satisfied or somewhat satisfied with the help that they received for the 14 daily tasks listed in the ADL scale $(94.4 \%$ of the partially disabled elderly, $95.6 \%$ of the fully disabled elderly).

\subsubsection{Emotional support}

Few disabled elderly respondents had a large number of friends. Seven-point-two percent of the partially disabled and $29.4 \%$ of the fully disabled had no close friends. Twenty-eight-point-one percent of the partially disabled elderly and $27.2 \%$ of the fully disabled elderly said they had only 1-2 close friends. Only a few 
Table 5. Relationships constituting the emotional support network of disabled elderly $(n=347)$

\begin{tabular}{lrccc}
\hline Relationships & \multicolumn{1}{c}{$n$} & \% of total & \% of relatives & \% of non-relatives \\
\hline Immediate family & 1,209 & 98.5 & 100 & \\
Spouse & 140 & 11.4 & 11.6 & \\
Son & 459 & 37.4 & 38.0 & \\
Daughter & 383 & 31.2 & 31.7 & \\
Daughter-in-law & 119 & 9.7 & 9.8 & \\
Son-in-law & 45 & 3.7 & 3.7 & 100 \\
Grandchildren & 46 & 3.7 & 1.4 & 57.9 \\
Other relatives & 17 & 1.4 & & 15.8 \\
Non-relatives & 19 & 0.9 & & 10.5 \\
Neighbors & 11 & 0.2 & & 5.3 \\
Colleagues & 3 & 0.2 & & \\
Friends & 2 & 0.2 & & \\
Nurse & 2 & 0.1 & & \\
Someone else & 1 & & & \\
Total & 1,228 & & & \\
\hline
\end{tabular}

Table 6. Bivariate analyses of social support factors in relation to ADL scale score for the elderly

\begin{tabular}{|c|c|c|c|c|c|}
\hline Social support factors & Normal & Partially disabled & Fully disabled & $\chi^{2}$ & $p$ \\
\hline \multicolumn{6}{|l|}{ Financial support } \\
\hline Source of income & & & & 16.046 & $<0.001$ \\
\hline Pension or other remuneration & $769(71.0 \%)$ & $156(14.4 \%)$ & $158(14.6 \%)$ & & \\
\hline Other sources & $626(57.8 \%)$ & $205(18.9 \%)$ & $252(23.3 \%)$ & & \\
\hline \multicolumn{6}{|l|}{ Routine support } \\
\hline Main caregiver when sick & & & & 64.828 & $<0.001$ \\
\hline Spouse & $865(79.8 \%)$ & $136(12.6 \%)$ & $82(7.6 \%)$ & & \\
\hline Someone else & $632(58.4 \%)$ & $192(17.7 \%)$ & $259(23.9 \%)$ & & \\
\hline \multicolumn{6}{|l|}{ Emotional support } \\
\hline Willingness to talk to someone else when upset & & & & 10.293 & 0.006 \\
\hline Yes & $754(69.6 \%)$ & $164(15.1 \%)$ & $165(15.3 \%)$ & & \\
\hline No & $631(58.3 \%)$ & $179(16.6 \%)$ & $273(25.2 \%)$ & & \\
\hline
\end{tabular}

ADL, Activities of Daily Living.

disabled elderly respondents responded that they had more than six friends $(7.5 \%$ of all respondents, $7.2 \%$ of the partially disabled elderly, $7.8 \%$ of the fully disabled elderly). When they faced difficulties, $92.2 \%$ of the disabled elderly were willing to ask a son(s)/daughter(s) for help $(88.5 \%$ of the partially disabled elderly, $95.6 \%$ of the fully disabled elderly). Most of the disabled elderly responded that they were on friendly terms with their neighbors $(62.3 \%$ of the partially disabled elderly, $51.1 \%$ of the fully disabled elderly).

In this study, social support networks were measured using the technique devised by Poel, which involves identification of the people in one's personal network (17). A typical question about one's emotional support network asked elderly respondents "when you are not in a good mood, who would you like to talk to?" Respondents were allowed multiple answers from among 12 possible answers: spouse, son(s)/daughter(s), parents, siblings, other relatives, colleagues, superiors, subordinates, classmates, friends, neighbors, and other non-relatives. As shown in Table 5, relatives were chosen most often (98.5\%); a son was chosen most often $(38 \%)$, followed by a daughter $(31.7 \%)$, and a spouse (11.6\%). Relationships with non-relatives played a relatively minor role in the support network; neighbors accounted for the highest proportion (57.9\%) of non-relatives.

\subsection{Bivariate analysis of the association between social support and disability}

Table 6 shows the results of bivariate analysis of the association between social support factors and the ADL score for the elderly. The ADL score for elderly respondents with personal income (including a salary, pension, or earnings) was lower than that of elderly respondents who received financial support from their spouse, son(s)/daughter(s), or the government ( $p<$ 0.001 ). Disabled elderly respondents who were mainly cared for by their spouse had a significantly higher ADL score than disabled elderly who were cared for by someone else $(p<0.001)$. Disabled elderly who were willing to talk to someone else when upset had a lower ADL score than disabled elderly who were reluctant to talk when upset $(p=0.006)$.

\subsection{Multivariate analysis of the association between} social support and disability

Table 7 shows the results of multivariate logistic 
Table 7. Multivariate logistic regressions of the effect of receiving social support on ALD scale score for the disabled elderly

\begin{tabular}{lccc}
\hline & & OR $(95 \% \mathrm{CI})$ & \\
\cline { 2 - 4 } & Financial support & Routine support & Emotional support \\
\hline ADL score $=14$ & Referent & Referent & Referent \\
$14<$ ADL score $<22$ & $0.706(0.432,1.154)$ & $0.485(0.325,0.724)$ & $0.808(0.469,1.394)$ \\
ADL score $\geq 22$ & $2.346(1.160,4.743)$ & $0.369(0.236,0.578)$ & $3.648(1.560,8.532)$ \\
\hline
\end{tabular}

${ }^{*}$ ADL scale score $=14$ : fully functioning; $14<$ ADL score $<22$ : partially disabled; ADL score $\geq 22$ : fully disabled. ADL, Activities of Daily Living.

regression analysis of the effect of receiving social support on the ALD score for the disabled elderly. After adjusting for gender, age, level of education, marital status, and monthly income, fully disabled respondents were 2.346 times more likely to receive financial support than fully functioning respondents $(p$ $=0.018,95 \%$ CI: 1.160-4.743). However, the partially disabled elderly and the fully disabled elderly did not differ significantly in terms of financial support ( $p=$ $0.165>0.05)$. Partially disabled respondents were 0.485 $(p<0.001)$ times and fully disabled respondents were $0.369(p<0.001)$ times less likely to be fully satisfied with daily care than fully functioning respondents. In addition, fully disabled respondents were 3.648 times more likely to receive emotional support than fully functioning respondents ( $p=0.003,95 \% \mathrm{CI}$ : 1.560 8.532). However, the partially disabled elderly and the fully disabled elderly did not differ significantly in terms of emotional support $(p=0.444>0.05)$.

\section{Discussion}

Most of the respondents had formal financial support such as a salary and pension, they had medical insurance, and they received financial support from the local government or community, but respondents also had a middle or low level of income and their insurance was insufficient. Multivariate analysis revealed significant differences between fully functioning and disabled individuals, but the financial support received by the partially disabled elderly did not differ significantly from that received by respondents who were able to live independently. Thus, under current conditions in China where "aging of the population is proceeding faster than the pace of development," there is an imminent need for a better financial support system for the disabled elderly, and especially those who are partially disabled or in financial distress.

Moreover, the current long-term care service for disabled elderly is not reimbursed by medical insurance. Disabled elderly had to cover medical expenses resulting from hospitalization due to an illness through out-of-pocket payments or payments by their families. Although such solutions are feasible at present, the increase in the disabled elderly population and the decrease in the number of son(s)/daughter(s) will result in a greater financial burden posed by the long-term care needs of the disabled elderly as well as increasing reliance on nursing homes. Thus, a helpful approach would be for medical insurance to cover long-term care in the future. Other potential solutions could be the establishment of an independent insurance system for long-term care or a combination of long-term care insurance and social care insurance for the disabled elderly.

The extent of routine support was somewhat greater than the extent of financial support. Most elderly respondents lived with their family/children, they responded that they could often receive help from their son(s)/daughter(s), they were cared by their son(s)/daughter(s) or spouse when sick, and they were fully satisfied or somewhat satisfied with the help they received. A point worth mentioning is that care by one's family or son(s)/daughter(s) was the main form of routine support received by the disabled elderly. Previous studies have found older Chinese with the ability to live independently also tend to reside with family rather than live in a nursing home (18). This phenomenon can be explained by the fact that residing with and caring for elderly parents is still the predominant way that adult son(s)/daughter(s) in modern China express filial piety - a key virtue in Chinese culture (19).

However, the current analysis indicated that partially or fully disabled respondents were much less likely to be fully satisfied with daily care, which was mainly care provided by their family, compared to functioning respondents. Previous studies have suggested that the disabled elderly who need long-term care and who heavily depend on daily care probably need institutional care. As an example, a study in Taiwan found that caring for stroke patients in their own homes was both more expensive and also less effective in improving ADL scores than caring for patients in nursing homes or in chronic care units of hospitals (20). In the current study, nearly $30 \%$ of the respondents who would have preferred to live in a nursing home (results not published). Asked further about their reasons for not living in a nursing home, nearly half of the disabled elderly responded they could not afford that care (results not published). Thus, improving the affordability of institutional care is likewise essential for improvement 
of the recovery, quality of life, and survival of disabled older adults.

Almost one third of the fully disabled had no close friends and nearly half were not on good terms with their neighbors. A study on non-institutionalized, fully functioning Japanese elderly found that among all social support and network characteristics, adequacy of emotional support contributed the most to the prevention of depression and suicide among older adults (21). The current bivariate analysis likewise found that disabled elderly who were willing to talk to someone else when they were not in a good mood had a lower ADL score than that of disabled elderly who were reluctant to talk. This finding is consistent with a previous study suggesting that emotional support was not associated with disability but did it did prevent a decrease in ADL (14). Since the physical activity and social interaction of disabled elderly are limited, the lack of emotional support for the disabled is a pressing issue. Moreover, multivariate analysis suggested that partially disabled respondents needed more emotional support than fully functioning respondents but that the two groups did not differ in terms of the emotional support they actually received. All of these findings emphasize the need to provide sufficient emotional support to the fully disabled elderly as well as to the partially disabled elderly.

In addition, the emotional support network of the disabled elderly mainly consisted of immediate family and relatives, suggesting a lack of diversity in their social network. Though evidence is inconsistent across the literature (22), most studies have pointed out the importance of diversity in the social networks of the elderly $(23,24)$. Increasing the diversity of social networks may prevent disability among older people.

There are several limitations inherent in the current study. First, data were collected using a cross-sectional survey. With such data, only associations, as opposed to causality, could be inferred. Second, the nature of the questionnaire inevitably led to certain drawbacks, including recall bias and social desirability bias. Third and last, China is a large country with significant differences among its regions and areas. Although Beijing is a cosmopolitan city, caution should be taken in generalizing findings from the Beijing area to other areas of China.

In summary, the current study provided a thorough look at the current status of social support among disabled Chinese elderly. The results highlight the need to pay greater attention to social support for partially disabled individuals and daily care for both partially and fully disabled individuals.

\section{Acknowledgements}

This study was funded by grants from the National Nature Science Foundation of China (71373184,
71774034), the think tank project of the Data Center for Management Science, NSFC-PKU of the National Nature Science Foundation of China (2015KEY05), and the Beijing Natural Science Foundation (9162018).

\section{References}

1. Fang EF, Scheibye-Knudsen M, Jahn HJ, Li J, Ling L, Guo H, Zhu X, Preedy V, Lu H, Bohr VA, Chan WY, Liu Y, Ng TB. A research agenda for aging in China in the 21st century. Ageing Res Rev. 2015; 24:197-205.

2. China Research Center on Aging. http://www.crca.cn (accessed September 1, 2017).

3. Wu YS. Report on China's Efforts to Address Aging. Social Sciences Academic Press (Beijing), 2013. (in Chinese)

4. Kempen GI, Ranchor AV, van Sonderen E, van Jaarsveld CH, Sanderman R. Risk and protective factors of different functional trajectories in older persons: Are these the same? J Gerontol B Psychol Sci Soc Sci. 2006; 61:P95-101.

5. Stuck AE, Walthert JM, Nikolaus T, Bula CJ, Hohmann C, Beck JC. Risk factors for functional status decline in community-living elderly people: A systematic literature review. Soc Sci Med. 1999; 48:445-469.

6. McLaughlin D, Leung J, Pachana N, Flicker L, Hankey G, Dobson A. Social support and subsequent disability: It is not the size of your network that counts. Age Ageing. 2012; 41:674-677.

7. Levasseur M, Genereux M, Bruneau JF, Vanasse A, Chabot E, Beaulac C, Bedard MM. Importance of proximity to resources, social support, transportation and neighborhood security for mobility and social participation in older adults: Results from a scoping study. BMC Public Health. 2015; 15:503.

8. Zunzunegui MV, Rodriguez-Laso A, Otero A, Pluijm SMF, Nikula S, Blumstein T, Jylha M, Minicuci N, Deeg DJH, Group CW. Disability and social ties: Comparative findings of the CLESA study. Eur J Ageing. 2005; 2:4047.

9. James BD, Boyle PA, Buchman AS, Bennett DA. Relation of late-life social activity with incident disability among community-dwelling older adults. J Gerontol A Biol Sci Med Sci. 2011; 66:467-473.

10. Mendes de Leon CF, Glass TA, Berkman LF. Social engagement and disability in a community population of older adults: The New Haven EPESE. Am J Epidemiol. 2003; 157:633-642.

11. Hsu HC, Tung HJ. What makes you good and happy? Effects of internal and external resources to adaptation and psychological well-being for the disabled elderly in Taiwan. Aging Ment Health. 2010; 14:851-860.

12. Mendes de Leon CF, Glass TA, Beckett LA, Seeman TE, Evans DA, Berkman LF. Social networks and disability transitions across eight intervals of yearly data in the New Haven EPESE. J Gerontol B Psychol Sci Soc Sci. 1999; 54:S162-172.

13. Avlund K, Lund R, Holstein BE, Due P. Social relations as determinant of onset of disability in aging. Arch Gerontol Geriatr. 2004; 38:85-99.

14. Mendes de Leon CF, Gold DT, Glass TA, Kaplan L, George LK. Disability as a function of social networks and support in elderly African Americans and Whites: 
The Duke EPESE 1986--1992. J Gerontol B Psychol Sci Soc Sci. 2001; 56:S179-190.

15. Lawton MP, Brody EM. Assessment of older people: Self-maintaining and instrumental activities of daily living. Gerontologist. 1969; 9:179-186.

16. Berkman LF, Glass T, Brissette I, Seeman TE. From social integration to health: Durkheim in the new millennium. Soc Sci Med. 2000; 51:843-857.

17. Poel M. Personal Networks: A Rational-Choice Explanation of their Size and Composition. Swets and Zeitlinger (Lisse), 1993.

18. Zhang L, Zeng Y, Fang Y. The effect of health status and living arrangements on long term care models among older Chinese: A cross-sectional study. PLoS One. 2017; 12:e0182219.

19. Zhang Z, Gu D, Luo Y. Coresidence with elderly parents in contemporary China: The role of filial piety, reciprocity, socioeconomic resources, and parental needs. J Cross Cult Gerontol. 2014; 29:259-276.

20. Chiu L, Shyu WC, Liu YH. Comparisons of the cost- effectiveness among hospital chronic care, nursing home placement, home nursing care and family care for severe stroke patients. J Adv Nurs. 2001; 33:380-386.

21. Oxman TE, Berkman LF, Kasl S, Freeman DH, Jr., Barrett J. Social support and depressive symptoms in the elderly. Am J Epidemiol. 1992; 135:356-368.

22. Rafnsson SB, Shankar A, Steptoe A. Longitudinal influences of social network characteristics on subjective well-being of older adults: Findings from the ELSA study. J Aging Health. 2015; 27:919-934.

23. Simons RL. Specificity and substitution in the social networks of the elderly. Int J Aging Hum Dev. 1983; 18:121-139.

24. Escobar-Bravo MA, Puga-Gonzalez D, Martin-Baranera M. Protective effects of social networks on disability among older adults in Spain. Arch Gerontol Geriatr. 2012; 54:109-116.

(Received September 20, 2017; Revised October 17, 2017; Accepted October 26, 2017) 